\title{
Multiple land use change simulation with Monte Carlo approach and CA-ANN model, a case study in Shenzhen, China
}

Tianhong $\mathrm{Li}^{1,2^{*}}$ and Wenkai Li ${ }^{3}$

\begin{abstract}
Background: CA-ANN models which integrate Cellular Automata (CA) and Artificial Neural Networks (ANNs) for simulating land use change, usually urban and non-urban, predict the final land use type of a cell by the greatest similarity or probability after model parameters were defined in the training stage. In this study, the Monte Carlo approach was introduced into a CA-ANN model to simulate multiple land use changes with a case study in Shenzhen, China. The final land use type of a cell was jointly determined by the Monte Carlo approach and artificial neural network.

Results: The model performance were evaluated based on cell-to-cell comparison between simulated maps and actual ones by overall accuracy and kappa coefficient. The input maps of 1996, 2000 and 2004 were combined into three scenarios, the overall accuracies and kappa coefficients were all greater than $81.91 \%$ and 0.71 respectively. The land use maps of from 2004 to 2020 with 4 years interval were simulated and the results showed that build up will increase steadily while woodland will decrease. The impacts of spatial variables, neighborhood size and cell size on model performance were obtained by sensitive analysis.
\end{abstract}

Conclusions: The simulation performance were all acceptable compared with the existing studies. The model performance would increase slightly as either neighborhood size or cell size increased, and that proximities to railways and city center were the main factors driving the dynamics of land use change in the study area.

Keywords: Land use change; Cellular automata; Artificial neural network; Monte Carlo; Simulation

\section{Background}

Since the first theoretical approaches to CA-based models for simulating urban sprawl were proposed in 1980s and the first operational urban CA models were applied to real-world urban system in 1990s, lots of studies have been conducted to modify CA structure so as to address complex urban systems and Land use cover changes (LUCC) (Almeida et al. 2008; Batty 1997; Gong et al. 2009; Stevens et al. 2007; Torrens and O'Sullivan 2001; Verburg et al. 2004; Wu 1996, 1998a, b; Yang et al. 2008). The advantages of CA-based models including their simplicity, flexibility and intuitiveness and particularly their ability to incorporate the spatial and temporal dimensions of the

\footnotetext{
*Correspondence: Ith@pku.edu.cn

${ }^{1}$ College of Environmental Sciences and Engineering, The Key Laboratory for Water and Sediment Sciences, Peking University, Beijing 100871, China

${ }^{2}$ Shenzhen Graduate School of Peking University, Shenzhen 518055, China Full list of author information is available at the end of the article
}

processes have been agreed and the studies in this issue are still proliferating.

Temporal and spatial complexities of urban land use change can be well modeled by properly defining transition rules in CA models. To obtain appropriate transition rules, besides the conventional statistical methods (De Almeida and Gleriani 2005; He et al. 2008; Wu 2002), various approaches have also been taken including fuzzy logic (Al-Ahmadi et al. 2009; Al-kheder et al. 2008; Liu and Phinn 2003; Wu 1996 and Wu 1998a), support vector machine (Yang et al. 2008) and Artificial Neural Networks (ANNs) especially Back Propagation (BP) networks ( $\mathrm{Li}$ and Yeh 2001 and $\mathrm{Li}$ and Yeh 2002; Li and Liu 2006; Liu et al. 2008a; Liu et al. 2008b; Pijanowski et al. 2002; Yeh and Li 2003 and Yeh and Li 2004; Wang et al. 2011).

In the most previous studies, land use types of urban and non-urban were simulated ( $\mathrm{He}$ et al. 2008; $\mathrm{Li}$ and 
Yeh 2001; Li and Liu 2006; Liu et al. 2008a and Liu et al. 2008b; Pijanowski et al. 2002; Wu 2002; Yeh and Li 2003). In recent years, city residents pay more and more attention to their living environment, therefore, in simulation, other land use types especially those with high ecological services such as forest, water body and wetland ( $\mathrm{Li}$ et al. 2010) should not be generalized as nonurban any more. However, less than $40 \%$ among the 33 CA-based urban models reviewed by Santé et al. (2010) were capable of dealing with multiple land uses. On the other hand, land use change results from the complex interaction of many factors including policy, management, economics, culture, human behaviors and the environment. Whether a cell changes its state is not only determined by transition probability but also bears randomness. In this view, transition rules can include a stochastic component and deterministic rules (Santé et al. 2010). The most previous studies considered the deterministic rules by maximum probability. A few of them treated the stochastic component, for instance, $\mathrm{Li}$ and Yeh (2002) added a random variable into the probability function in ANN-CA model, Wu (2002) combined Monte Carlo approach with probability generalized by statistical method in urban and non-urban simulations.

With Shenzhen City, a typical rapid urbanization area in China or even in the whole world, as the case, this study aims to simulate multiple land use dynamics by combining Monte Carlo approach to CA-ANN model, and to choose appropriate model parameters with sensitivity analysis on predicating variables, neighborhood size and cell size.

\section{Results and discussions}

\section{Model performance}

The simulation accuracy was evaluated based on cell-bycell comparison which was typically used (Li and Yeh 2002; Yang et al. 2008). It evaluates the similarity between the actual and simulated situations at the scale of a single cell. The results of the cell-by-cell comparison with the test cells for three scenarios were given in Table 1.

For Scenarios I, II and III, the overall accuracy is $81.91 \%, 83.13 \%$ and $85.33 \%$ respectively. The kappa coefficients were calculated to quantify the actual degree of agreement (Congalton 1991). The coefficient was 0.71, 0.73 and 0.76 for Scenarios I, II and III in the same order. The similar accuracies for the two periods suggested that the land use change mechanism is relatively stable in this region and that the models trained by different senarios can be used to forecast future land use changes. Yang et al. (2008) used SVM and CA to simulate urban and non-urban land use in Shenzhen with different data sets (1993 and 2004) and reported that the overall accuracy were $87.25 \%$ and $84.90 \%$ and kappa coefficients were 0.70 and 0.68 . Though their overall accuracies are a little higher than our results, but their kappa coefficients are all lower than those of the proposed model.

The actual maps and simulated maps are shown in Figures 1 and 2. Generally, the simulated maps are spatially conformity to the actual maps. The simulated maps in Figure 2 showed that Build-up and Woodland dominated the study area with their areal percentage being both around $44 \%$, while the Water body, Cropland and Wetland occupied around $8 \%, 2 \%$ and $2 \%$ of the whole study area. They are generally consistent with the real land use maps. In the Figure 2 (I), the kappa coefficients of the Wetland, Water body and Woodland were all great than 0.70 , suggesting these types of land use have been well simulated. In Figure 2 (II), the kappa coefficients of Woodland, Water body and Build-up were all great than 0.70. In Figure 2 (III), the coefficients of Cropland is 0.46 while those of the other four land uses were all greater than 0.70 . On the other hand, the random land use type in Figure 2 (II) and Figure 2 (III) have decreased compared to Figure 2 (I).

\section{Sensitivity analysis}

With the model trained by Scenarios III which produced relatively best performance, the impacts of spatial variables, neighborhood size and cell size were discussed.

\section{Spatial variables}

The input layer of BP network contained fifteen neurons associated with the variables, while the output layer contained five neurons associated with the map of transition

Table 1 Class kappa coefficients and overall accuracy for each scenarios

\begin{tabular}{llllllll}
\hline Scenario* & Woodland & Cropland & Wetland & Water body & Build-up & Overall Kappa & Overall accuracy (\%) \\
\hline I & 0.72 & 0.49 & 0.87 & 0.79 & 0.68 & 0.71 & 81.91 \\
II & 0.76 & 0.33 & 0.55 & 0.71 & 0.77 & 0.73 & 83.13 \\
\hline
\end{tabular}

*Scenario I: training samples from 1996 and 2000 land use maps are input and output of the model respectively, the map of 1996 was input to the model and the map of 2000 was predicted and evaluated with the actual map of 2000 using testing samples.

Scenario II: training samples from 1996 and 2000 land use maps are input and output of the model respectively, the map of 2000 was input to the model and the map of 2004 was predicted and evaluated with the actual map of 2004 using testing samples.

Scenario III: training samples from 2000 and 2004 land use maps are input and output of the model respectively, the map of 2000 was input to the model and the map of 2004 was predicted and evaluated with the actual map of 2004 using testing samples. 


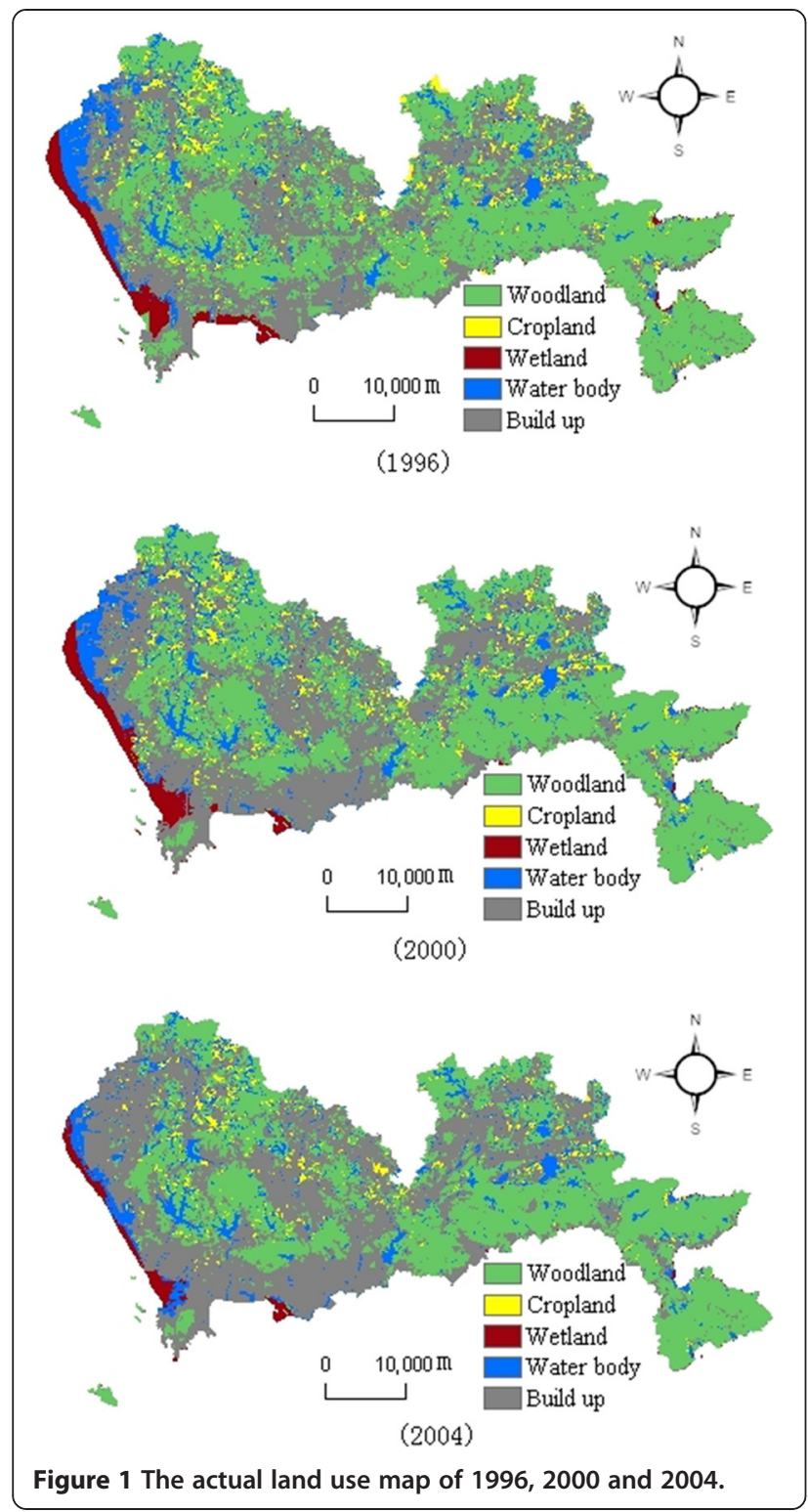

probabilities for the considered types of land use (Table 2). In order to investigate the effects of spatial variables on model performance, we compared the model fitness of the nine versions of the reduced-variable model with that with the full predictor variables. In Table 3, row "p" represented the model performance with complete predictor variables, while row "pi $=0$ " represented that with variable "pi" removed. The relative contribution of each predictor variable on the model performance was also ranked according to their differences between goodness of fit for the model with full variables and that for each of the reducedvariable models.

According to Table 3, the overall accuracy and kappa coefficients with complete predictor variables were higher than those with removed variables, indicating that

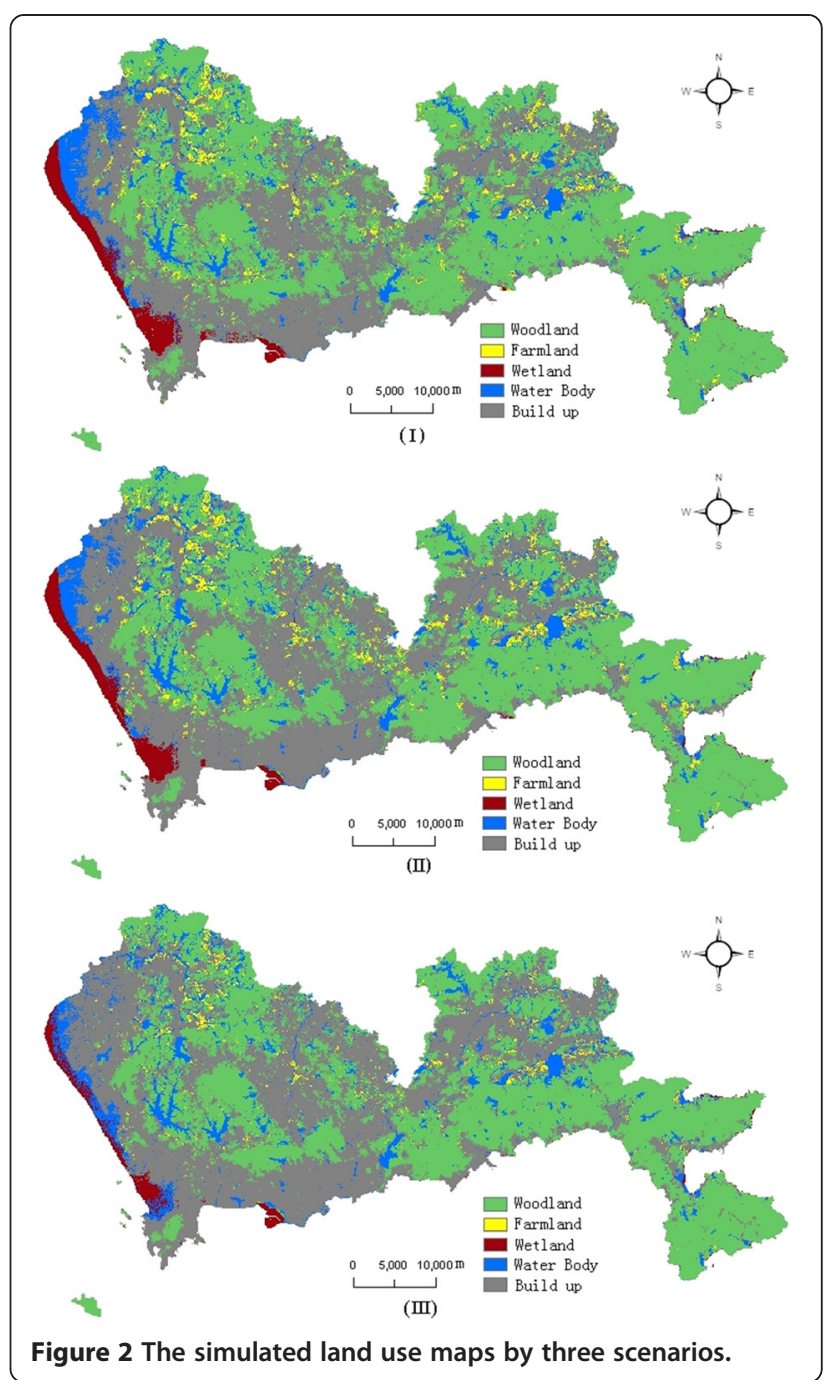

the variables selected in this study had positive effect on the model performance. The contribution of each predictor variable on the model performance was ranked as: $\mathrm{p} 7$ (Proximity to railways) $>\mathrm{p} 13$ (Proximity to city center) $>\mathrm{p} 9$ (Proximity to roads) $>\mathrm{p} 14$ (Proximity to towns) $>$ p10 (Proximity to streets) $>$ p 8 (Proximity to expressways) $>$ p12 (Proximity to lakes or reservoirs) $>$ p 15 (population density) $>$ p11 (Proximity to rivers). This result showed that Proximities to railways and city center were the main factors which have driven the dynamics of land use. This result was also approved in Shi's study (Shi et al. 2000).

\section{Neighborhood size}

Neighborhood interactions represent one of the main driving factors in a large group of land use change models based on cellular automata (Verburg et al. 2004). In many studies, the size of the neighborhood was 
Table 2 Input and output of the BP network

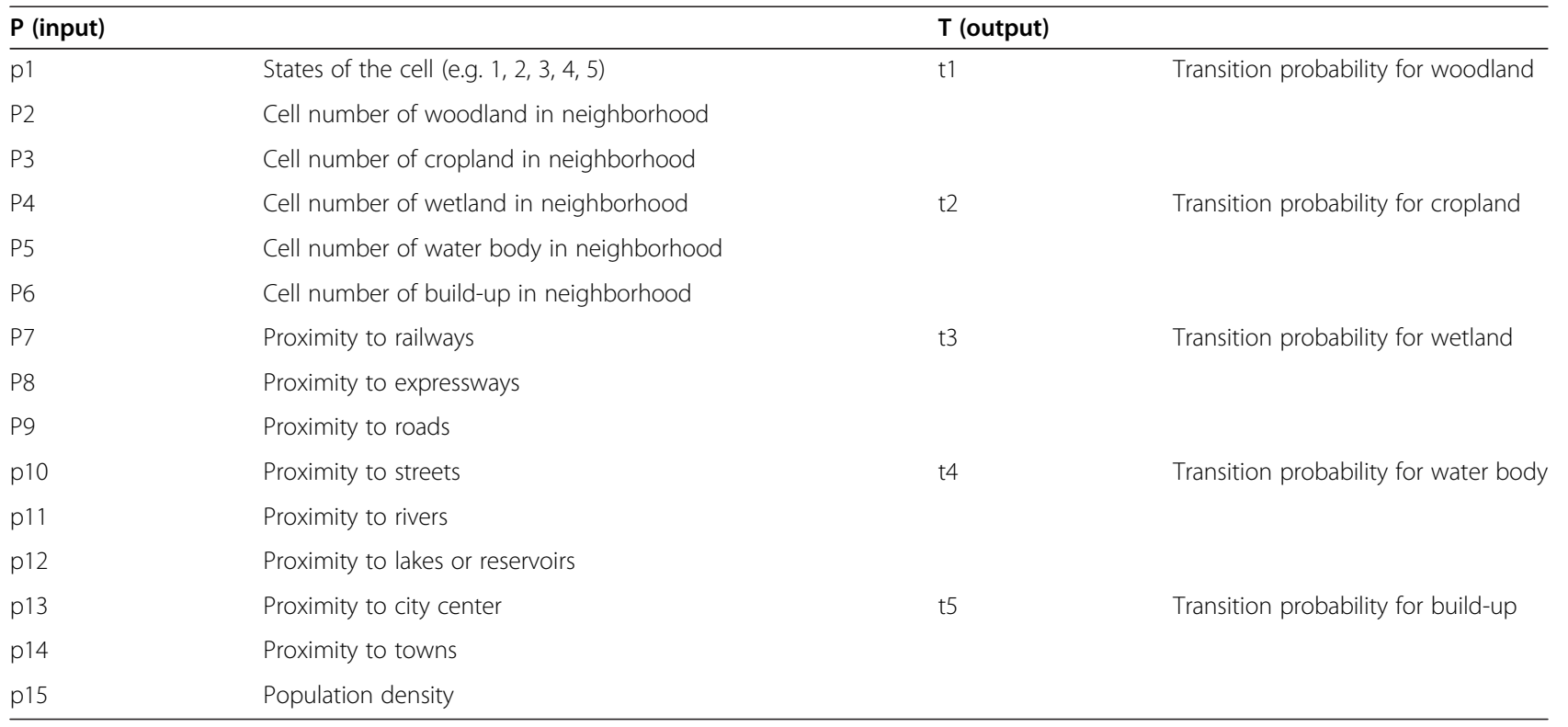

chosen arbitrarily and only the direct neighborhood of a location was taken into account (e.g. Von Neumann or Moore neighborhoods), while others have argued that human activities are influenced by wider spaces, this makes an appropriate definition of the neighborhood essential (Verburg et al. 2004; White and Engelen 2000). In this study, three sizes of Moore neighborhoods, $3 \times 3$, $5 \times 5$, and $7 \times 7$, were used to understand the effects of neighborhood size on the model performance.

The simulation map of land use in 2004 was cell-tocell compared to the actual map to evaluate the fitness of models with different neighborhood sizes. According to Table 4, the overall accuracy and Kappa coefficients increased slightly as the neighborhood size increased. However, this increase is too slight to make a significant impact. Considering the computing time cost, the smaller neighborhood size can be used.

Table 3 Effects of spatial variables on model performance

\begin{tabular}{llll}
\hline Spatial variables & Overall accuracy (\%) & kappa & Rank \\
\hline $\mathrm{p}$ & 0.8533 & 0.7576 & \\
$\mathrm{p} 7=0$ & 0.7896 & 0.6614 & 1 \\
$\mathrm{p} 8=0$ & 0.8467 & 0.7471 & 6 \\
$\mathrm{p} 9=0$ & 0.8338 & 0.7229 & 3 \\
$\mathrm{p} 10=0$ & 0.8416 & 0.7364 & 5 \\
$\mathrm{p} 11=0$ & 0.8512 & 0.7561 & 9 \\
$\mathrm{p} 12=0$ & 0.8496 & 0.7513 & 7 \\
$\mathrm{p} 13=0$ & 0.8226 & 0.7098 & 2 \\
$\mathrm{p} 14=0$ & 0.836 & 0.7279 & 4 \\
$\mathrm{p} 15=0$ & 0.8515 & 0.7541 & 8 \\
\hline
\end{tabular}

\section{Cell size}

The spatial scale is also an important factor which should be taken into account in the modeling of spatial problems. Thus, the fitness of models for different cell sizes $(100 \mathrm{~m} \times 100 \mathrm{~m}, 250 \mathrm{~m} \times 250 \mathrm{~m}$, and $500 \mathrm{~m} \times$ $500 \mathrm{~m}$ ) was evaluated based on cell-to-cell comparison as shown in Table 5.

In Table 5, the individual kappa coefficient for each type of land use increased as the cell size increased, and so did the overall accuracy and kappa coefficients, which indicated that increasing the cell size may slightly improve the fitness of the model. However, it was not favorite for guiding land use planning if the cell size was too large. As a result, a tradeoff was made between model performance and high spatial resolution output maps in actual simulations. In the following simulation, the cell size of $100 \mathrm{~m} \times 100 \mathrm{~m}$ was adopted because it will produce more detailed land use maps without apparently lowering predicting accuracy.

\section{Land use simulation}

With the map of land use in 2000 used as the input map and with the model parameters selected by the previous section (cell size $=100 \mathrm{~m} \times 100 \mathrm{~m}$, neighborhood size $=$ $3 \times 3,9$ GIS layers of predictor variables or constraints),

Table 4 Fitness of models with different neighborhood sizes

\begin{tabular}{lll}
\hline Size of neighborhood & Overall accuracy (\%) & Kappa coefficients \\
\hline $3 \times 3$ & 85.31 & 0.7572 \\
$5 \times 5$ & 85.33 & 0.7576 \\
$7 \times 7$ & 85.34 & 0.7578 \\
\hline
\end{tabular}


Table 5 Simulation accuracies with different cell sizes

\begin{tabular}{|c|c|c|c|c|c|c|c|}
\hline \multirow{2}{*}{$\begin{array}{l}\text { Cell } \\
\text { size }\end{array}$} & \multicolumn{5}{|c|}{ Individual Kappa coefficient } & \multirow{2}{*}{$\begin{array}{l}\text { Kappa } \\
\text { coefficient }\end{array}$} & \multirow{2}{*}{$\begin{array}{l}\text { Overall } \\
\text { accuracy }\end{array}$} \\
\hline & Woodland & Cropland & Wetland & Water body & Build-up & & \\
\hline $100 \mathrm{~m}$ & 0.79 & 0.46 & 0.76 & 0.78 & 0.74 & 0.7576 & 85.33 \\
\hline $250 \mathrm{~m}$ & 0.78 & 0.46 & 0.79 & 0.81 & 0.74 & 0.7590 & 85.39 \\
\hline $500 \mathrm{~m}$ & 0.82 & 0.54 & 0.84 & 0.82 & 0.75 & 0.7830 & 86.72 \\
\hline
\end{tabular}

the tested model (Scenario II ) ran for 5 cycles to simulate the land use changes from 2004 to 2020 in Shenzhen in every four years. The areal changing trends of the five land use types is shown in Figure 3.

Figure 3 show that build-up will become the dominating land use type in 2020, its area exceeding any of the other land use types. Decrease of farmland was the most fast, with the rate of $5.52 \%$ per year, followed by wetland with the decreasing rate of $2.59 \%$ per year. This result is consistent with the results of a prior study in Shenzhen (Bai 2000), in which a System Dynamics (SD) approach was used and predicted that Shenzhen would experience rapid urban growth from 1980 to 2030 and that areas of build-up would increase significantly while cropland would decline to almost zero.

\section{Conclusions}

The Monte Carlo approach was introduced to combine with transition probabilities generalized by ANN to decide the states of cells. The modified ANN-CA model proved capable of simulating multiple land use changes in Shenzhen with good performance. The variables selected in this study had positive effects on the model performance, among which the proximities to transportation and to city center were recognized as the major factors which drove the dynamics of land use. Moreover, model performance increased slightly as either neighborhood size or cell size increased. However, a compromise should be made between model performance, provision of spatial information details and computing time. The cell size of $100 \mathrm{~m} \times 100 \mathrm{~m}$ and $3 \times 3$ neighborhood size was chosen for the simulation of land use changes in the study area and land use maps from 2008 to 2020 with 4 year interval were forecasted and showed that the areas of woodland, cropland, wetland and water body tend to decline while the area of built-up tend to increase through 2004 to 2020 . These results can be referenced by local decision makers in pursuing ecological and human-centered urbanization.

\section{Methods}

\section{Cellular automata in land use simulation}

A cellular automata system consists of a regular grid of cells, each of which can be in one of a finite number of possible states, updated synchronously in discrete time steps according to a local, identical interaction rule. The

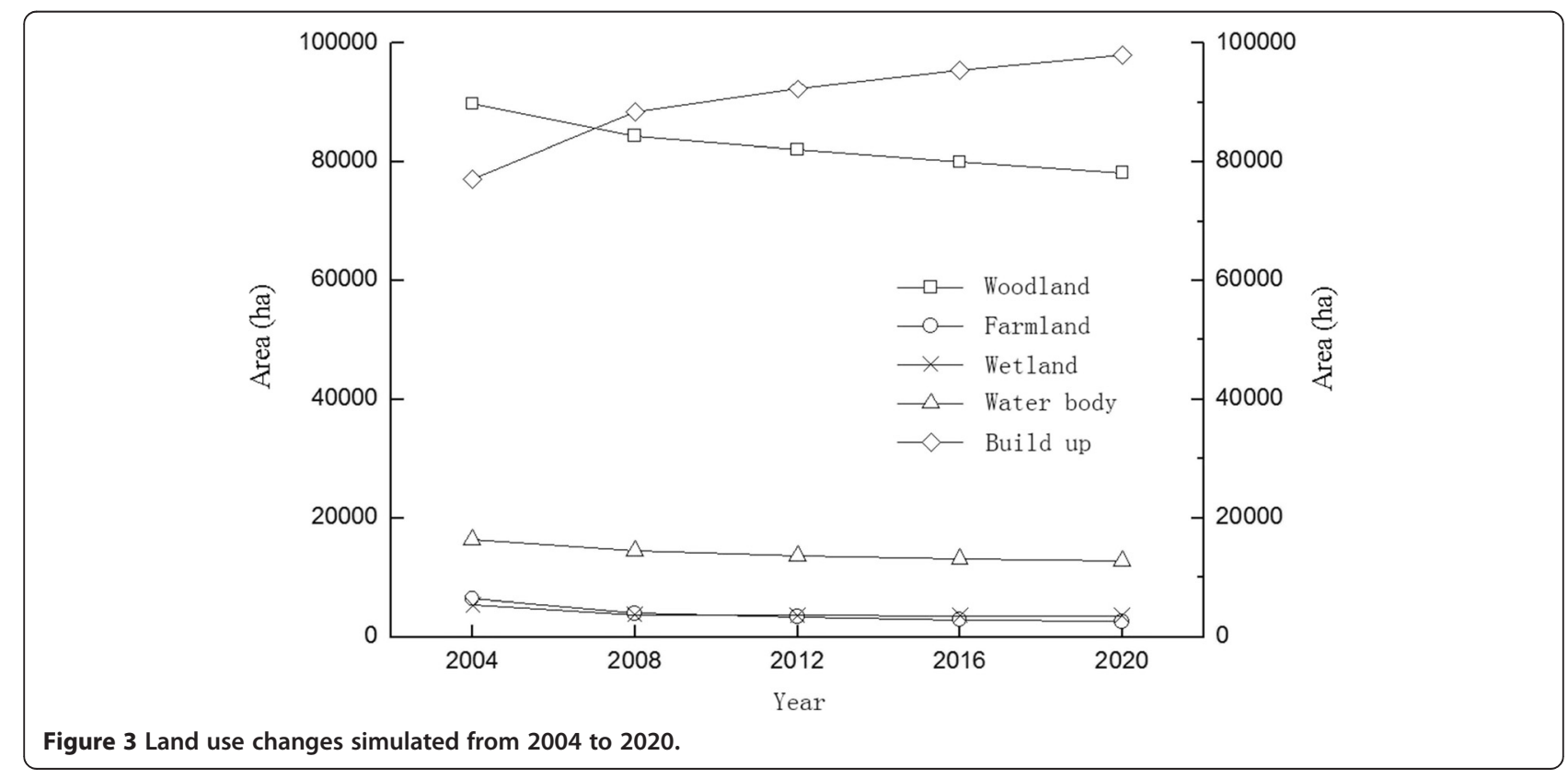


state of a cell is determined by the previous states of a surrounding neighborhood of cells (Wolfram 1984). The principle of cellular automata can be illustrated by Eq. 1:

$$
S_{t+1}=f\left(S_{t}, N\right)
$$

Where $S_{t}$ and $S_{t+1}$ represents one of the finite number of possible states at time $t$ and time $(t+1)$ respectively, $N$ represents the combined states of the neighborhood, and $f$ represents the transition rules.

A basic CA model consists of five fundamental elements: lattice, cell states, neighborhood, transition rules, and time steps. Because of the complexity of urban systems, the framework of basic CA is too simplified and constrained to represent real cities. To simulate complex geographical phenomena such as urban systems, it is necessary do some modification to the basic CA model, especially to modify the elicitation process of transition rules (Santé et al. 2010; Torrens 2000).

The lattice is the space where all of the cells are located. Theoretically, the lattice can be the Euclidean space with any dimension and any geometric shape though the lattice of rectangular grids is widely used.

The cell is the minimum unit in the CA system and it is regularly located on the Euclidean space, with discrete and finite states. To simulate the dynamics of multiple land use types, the state "s" can be defined as $\mathrm{s}=\{1,2,3, \ldots, n\}$, representing $n$ types of land use.

There are three common types of neighborhoods in conventional CA models: Von Neumann, Moore, and Circular neighborhoods (Kocabas and Dragicevic 2006; Liu and Phinn 2003).

The transition rules can be defined as the theoretical functions which determine the state of each cell according to the previous states of its own and its neighbors. Since changes of land use may result from the complex interaction of many factors, including policy, management, economics, culture, human behavior, and the environment (Pijanowski et al. 2002), the classic CA transition rules should be modified. However, it is not possible to recognize and incorporate all of the factors which drive land use changes. In practice, therefore, variables were usually chosen with the help of literature review and with considering the data availability.

\section{ANN-based CA model}

When ANNs were integrated to CA models, their predictive abilities can be improved (De Almeida and Gleriani 2005; Li and Yeh 2001; Pijanowski et al. 2002). In this study, the widely used CA-ANN model is modified in three aspects, namely, the multiple land use maps can be input and predicted, a threshold parameter is introduced to make the model controllable and the Monte Carlo approach is introduced to determine the final state of the cell. The learning aspect was based on a BP network involving training and testing with different datasets. Figure 4 illustrates the framework of the proposed model.

\section{Monte Carlo}

Since the process of land use change in the real world is complex and stochastic, the deterministic transition rules in conventional CA models were modified to probability functions (Eq. 2), and the converted states of each cell in the next step were obtained using the Monte Carlo approach (Eq. 3).

$$
\begin{aligned}
& S_{i}^{t+1}=\left\{p_{1}, p_{2}, \ldots, p_{j}, \ldots, p_{n}\right\} \\
& S_{i}^{\prime t+1}=\operatorname{MonteCarlo}\left(S_{i}^{t+1}\right)
\end{aligned}
$$

$p_{j}$ is the probabilities that a certain cell would transition to $j$ th land use type. A random number $\theta$ between 0 and 1 was obtained in the Monte Carlo approach.

For the state of a cell can be determined by the following rules, given $p_{i}>u p$, i $\epsilon\{1,2,3, \ldots, n\}$.

$$
\begin{aligned}
& S_{i}^{\prime t+1}=\operatorname{MonteCarlo}\left(S_{i}^{t+1}\right)=1 \text { if } 0 \leq \theta<p_{1} \\
& S_{i}^{\prime t+1}=\operatorname{MonteCarlo}\left(S_{i}^{t+1}\right)=j \text { if } \sum_{k=1}^{j-1} p_{k} \leq \theta<\sum_{k=1}^{j} p_{k}
\end{aligned}
$$

When combining Monte Carlo approach with transition potentials generalized by ANN, this study introduced a parameter " $u p$ " to make the model controllable. This parameter controls the number of cells on which Monte Carlo approach will be used. For all the land use types, if the transition probability generalized by BP network to one land use type of a cell is smaller than " $u p$ ", then the state of the cell would remain the same in the iterative cycle. Otherwise, the state of the cell was then determined by Monte Carlo approach. Thus, if "up" is set zero, all of the cells will be treated according to the rules of combination of Monte Carlo approach and transition probabilities. If " $u p$ " is set one, none of the cells will be converted. This process was iterated and land use map was predicted. Since only those cells with transition probabilities larger than " $u p$ " would be treated by the Monte Carlo approach and transition probabilities, as the value of " $u p$ " increases, the effect of Monte Carlo approach will wane, the output land use map will have less insular land use patches mainly near the boundary between land use types. Theoretically, if a cell has the same possibilities of changing into (or remaining unchanged) other land use types, the probability value should be the reciprocal of the number of land use types. To compromise, a value around the reciprocal of the number of land use types is recommended for "up". 


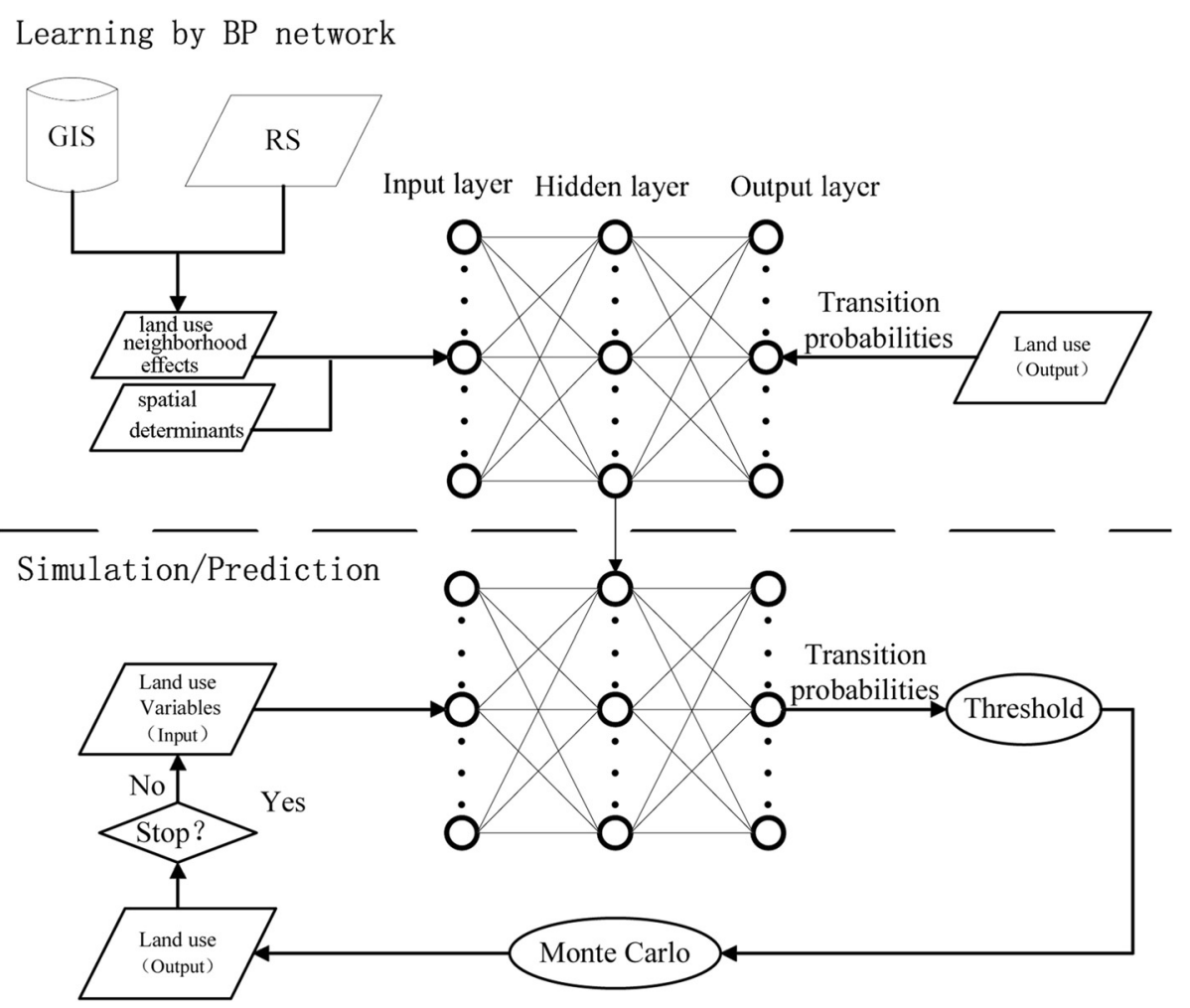

Figure 4 Framework of the model (modified on Li and Yeh 2002).

The exact value of "up" can be set by trial simulations for a certain study area.

CA will evolve in a sequence of discrete time steps. The real time of each step can be calibrated by historical data. Suppose that the periods of input and output data for CA training be $T_{1}$ and $T_{2}$, respectively. The interval " $N$ " between two consecutive time steps can be calculated: $N=\mathrm{T}_{2}-\mathrm{T}_{1}$. Thus, the sequent time of each step can be calculated: $\mathrm{T}_{3}=\mathrm{T}_{2}+N, \mathrm{~T}_{4}=\mathrm{T}_{3}+N, \mathrm{~T}_{5}=\mathrm{T}_{4}+$ $N$....After the structure, parameter, and transition rules are defined, the CA model will evolve dynamically.

The proposed model was implemented through the programming language of Visual Basic (VB) 6.0 and the technology of Component of Object Model (COM) on the platform MATLAB 6.5 .

\section{The study area}

Shenzhen $\left(22^{\circ} 27^{\prime} \mathrm{N} \sim 22^{\circ} 52^{\prime} \mathrm{N}\right.$ and $\left.113^{\circ} 46^{\prime} \mathrm{E} \sim 114^{\circ} 37^{\prime} \mathrm{E}\right)$ is a coastal city in the Pearl River Delta Region, southern China and locates directly north of Hong Kong (Figure 5). The total terrestrial area of Shenzhen is 0.19 million ha, and the coastline of the city totals 229.96 kilometers. Shenzhen has a mild, subtropical maritime climate with plenty of rain and sunshine. Since it was established in 1979 as the China's first Special Economic Region, Shenzhen has experienced rapid urbanization and economic development, and its land use structure has experienced, and continues to experience dramatic changes.

\section{Data sets and preprocessing}

The spatial data selected for this study consisted of land use datasets (on a scale of 1:50,000) in the year of 1996, 2000 and 2004, transportation network maps, river system and lake distribution maps, and administrative borderline maps (including the city center, towns, and residential blocks). These datasets were officially acquired mainly by aerial photograph interpretation aided by ground surveys and historical land use maps. In the data preparation, the same data interpretation methods and the same classification categories were adopted. The data were then edited, calibrated, and converted into raster data in ArcGIS for the subsequent spatial analysis.

The original land use categories included two levels of Chinese National Standard Categories. In this study, the datasets were reclassified into five categories: woodland, cropland, wetland, water body, and build-up. Therefore, the values of raster grids were coded as $1,2,3,4$, and 5, representing the five land use types in the order mentioned above. 


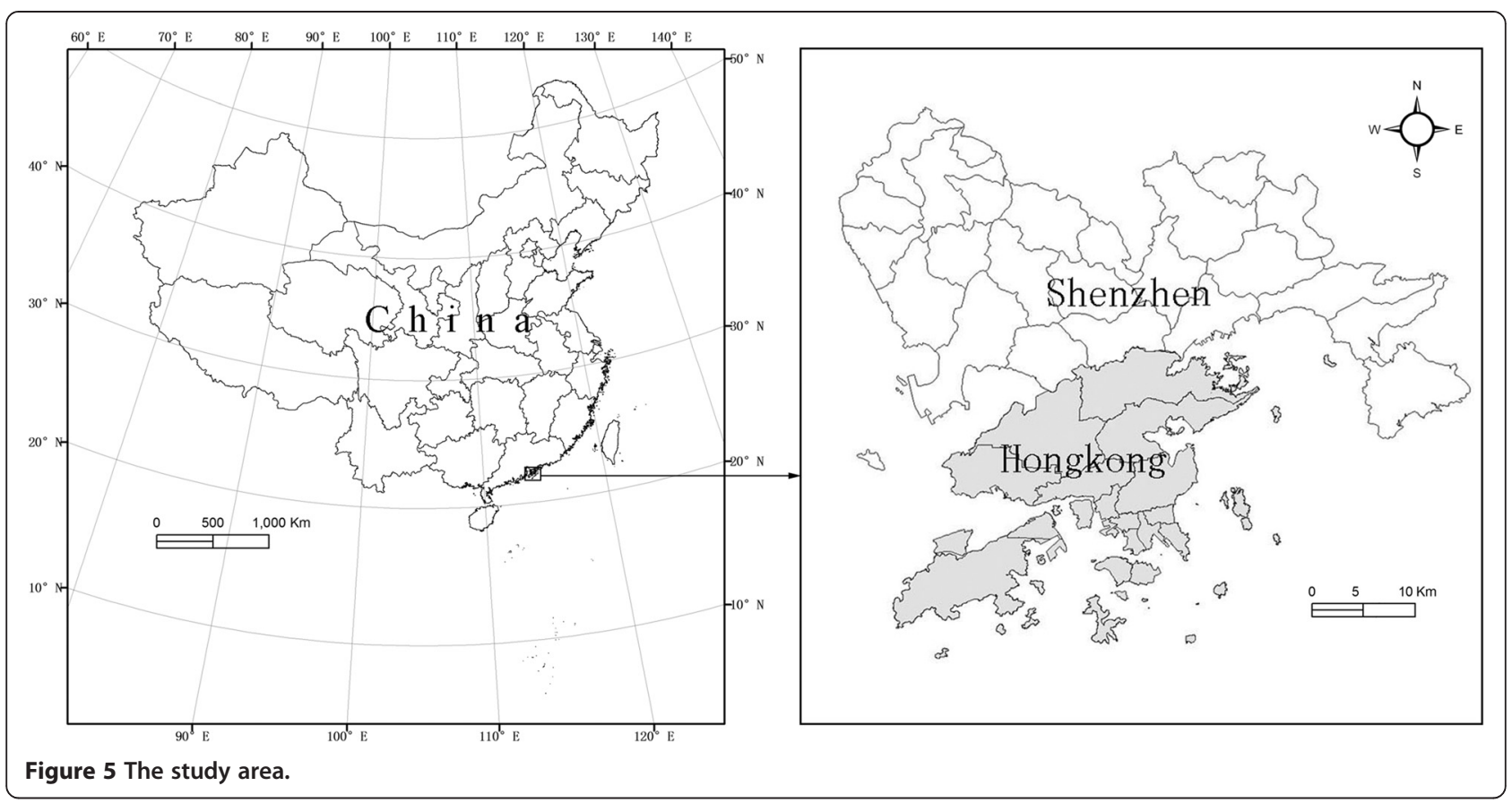

Moore neighborhood, which is the most frequent used, was adopted in this case study.

To build the transaction rules, variables were chosen with the help of literature review (Kocabas and Dragicevic 2007; Santé et al. 2010; Singh 2003; Shi et al. 2000; Yang et al. 2008) with considering the data availability. They are $\operatorname{Tr} 0$ (proximity to railways), $\operatorname{Tr} 1$ (proximity to expressways), $\operatorname{Tr} 2$ (proximity to roads), $\operatorname{Tr} 3$ (proximity to streets), $C$ (proximity to city centers), $T$ (proximity to towns), and $P$ (population density). Because major rivers and lakes are ecologically sensitive areas in the study area, they should be protected and any developing activities should not be restricted in these areas. To this end, two proximities, $R$ (proximity to rivers) and $L$ (proximity to lakes), were selected as constraints of the model. The modified CA rules can be described by

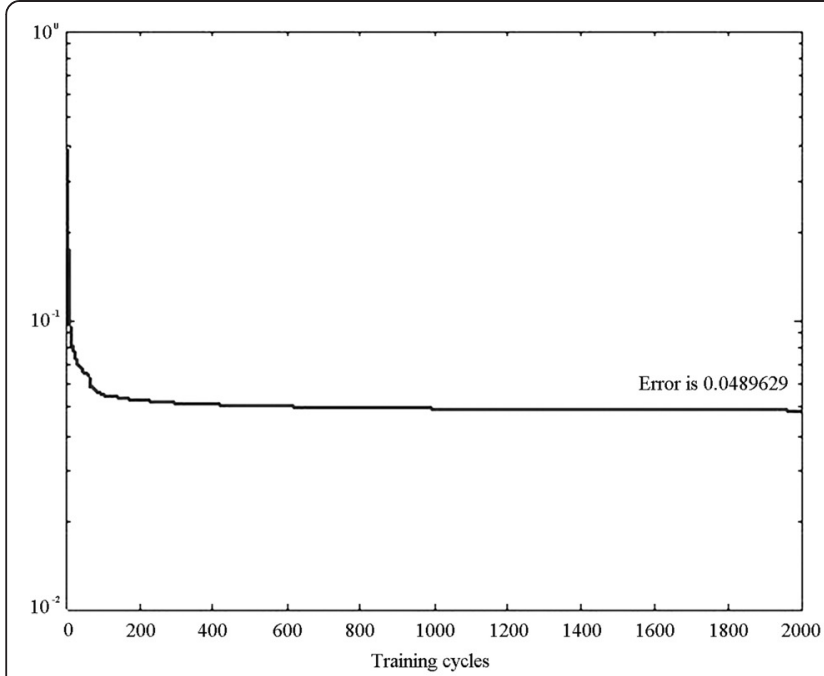

(A)

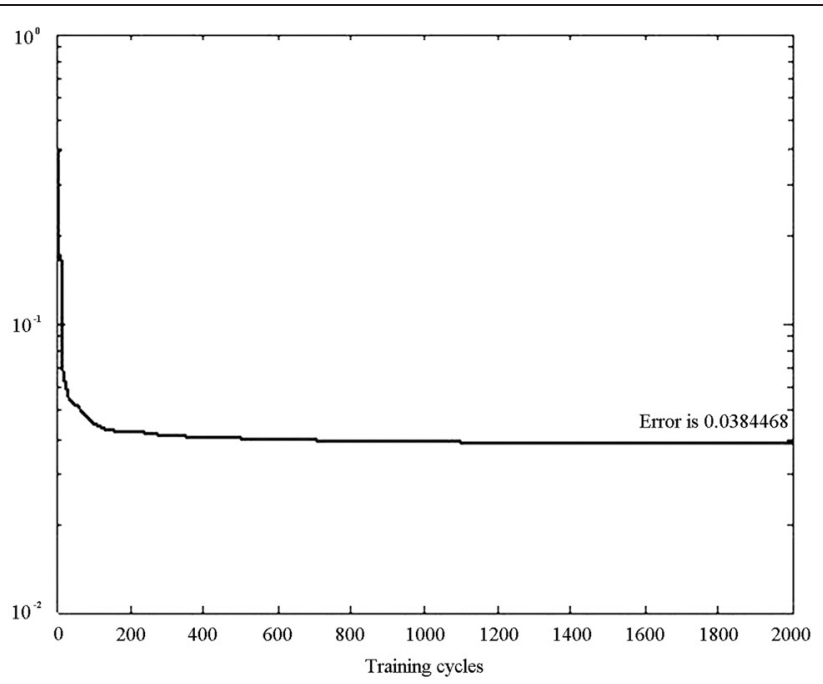

(B)

Figure 6 Training cycles and prediction error for two training groups (panel A for Group A and panel B for Group B). 
Eq. 6. As these spatial variables range extensively, they tend to be normalized to the same data range (e.g. integer values from 1 to 9 ).

$$
S_{i}^{t+1}=f\left(S_{i}^{t}, N_{i}^{t}, \operatorname{Tr} 0_{i}^{t}, \operatorname{Tr} 1_{i}^{t}, \operatorname{Tr} 2_{i}^{t}, \operatorname{Tr} 3_{i}^{t}, R_{i}^{t}, L_{i}^{t}, C_{i}^{t}, T_{i}^{t}, P_{i}^{t}\right)
$$

$i$ refers to cell " $i$ ", $t$ refers to time steps, $S$ refers to cell states, and $N$ refers to the combined states of the neighborhood, i.e. the pixel numbers of each land use category in the whole neighborhood.

For the eight proximity variables, the minimum Euclidean distance to each feature was calculated in ArcGIS and eight raster maps were produced. Since it was highly difficult to acquire the population for each cell, it was assumed that population locations complied with residential blocks. Thus, the variable of population density was obtained indirectly by calculation of residential block density based on the Kernel density. As these proximity variables range extensively and have different dimensions, these proximity and density variables were reclassified into 9 classes by Natural Breaks in ArcGIS and denoted by nine integers from 1 to 9 .

Since only those cells with transition probabilities larger than up would change their states in the next step through the Monte Carlo approach, the bigger value of up would produce fewer fragments while reduce the effect of Monte Carlo approach. Compromise is necessary, as above discussed. Because 5 land use types are simulated in this study, the value of $u p$ can be around 0.2 , after several trial simulations, up was set to 0.15 .

\section{Model training}

The CA transition potentials were learned through a BP network with training data. In this study, the proposed BP network had four layers: one input layer, two hidden layers, and one output layer. The neurons of input layer and output layer were define in Table 2. Through trials and experiments, the number of neurons in the first and second hidden layers was 15 and 8 respectively. Since the output of the neural network represented the transition probabilities for land use types, the Log-Sigmoid transfer function was adopted in order to guarantee of the output falling into the close range of $[0,1]$.

It is more appropriate to normalize and convert the input data into the close range of $[0,1]$ using Eq. 7 since this scaling procedure makes the input values compatible with the Sigmoid activation function that produces a value between 0 and 1 (Gong 1996).

$$
P_{i}^{\prime}=\frac{P_{i}-P_{\min }}{P_{\max }-P_{\min }}
$$

The land use maps of 1996, 2000 and 2004 were combined into two groups, namely, from 1996 to 2000
(Group A) and from 2000 to 2004 (Group B). The neighborhood size was set as $3 \times 3$, and the cell size was set to $100 \mathrm{~m} \times 100 \mathrm{~m}$. There are 194,989 cells in each map, of which 140,852 were chosen by stratified random sampling for training and the rest 54,137 cells were used for model test.

The algorithm of scaled conjugate gradient (SCG) (Moller 1993) was used to conduct the training. After about 2,000 running cycles, the ANN was stabilized and the error was reduced to 0.049 and 0.038 for Group A, $\mathrm{B}$ respectively (Figure 6).

\section{Competing interests}

The authors declare that they have no competing interests.

\section{Authors' contributions}

TL have made substantial contributions to conception and design, acquisition of data and data preprocessing, and manuscript drafting. WL have made substantial contributions to method implementation with programming, case study, data processing and manuscript drafting. Both of them have read and approved the final manuscript.

\section{Authors' information}

Tianhong Li got his Ph.D at Peking University in 1998, and now, he is an associated professor at Peking University. His research interests include water environment and ecological rehabilitation of Basins, and LUCC and its eco-environmental effects. He has published more than 70 papers in peer reviewed journals.

Wenkai Li got his M.S. at Peking University in 2008 and got his Ph.D at University of California Merced, USA in 2013. His major research interests include remote sensing and its applications to environmental studies. He has published more than 10 peer reviewed papers. Now, he is an associated professor at Sun Yat-Sen University.

\section{Acknowledgements}

Financial support was provided by the National Natural Scientific Fund under grant No.50979003. We would like to thank the anonymous reviewers also.

\section{Author details}

${ }^{1}$ College of Environmental Sciences and Engineering, The Key Laboratory for Water and Sediment Sciences, Peking University, Beijing 100871, China.

${ }^{2}$ Shenzhen Graduate School of Peking University, Shenzhen 518055, China. ${ }^{3}$ Geography and Planning School, Sun Yat-sen University, Guangzhou 510275, China.

Received: 7 June 2014 Accepted: 18 December 2014

Published online: 22 January 2015

\section{References}

Al-Ahmadi K, See L, Heppenstall A, Hogg J (2009) Calibration of a fuzzy cellular automata model of urban dynamics in Saudi Arabia. Ecol Complex 6(2):80-101, doi:10.1016/j.ecocom.2008.09.004

Al-kheder S, Wang J, Shan J (2008) Fuzzy inference guided cellular automata urban-growth modelling using multi-temporal satellite images. Int J Geogr Inf Sci 22(11-12):1271-93, doi:10.1080/13658810701617292

Almeida CM, Gleriani JM, Castejon EF, Soares BS (2008) Using neural networks and cellular automata for modeling intra-urban land-use dynamics. Int J Geogr Inf Sci 22(9):943-63, doi:10.1080/13658810701731168

Bai WQ (2000) Analysis on land use dynamics of Shenzhen. J Nat Resour 15 (2):112-6 (in Chinese)

Batty M (1997) Cellular automata and urban form: a primer. J Am Plan Assoc 63:266-74, doi:10.1080/01944369708975918

Congalton RG (1991) A review of assessing the accuracy of classification of remotely sensed data. Remote Sens Environ 37:35-46, doi:10.1016/0034-4257(91)90048-B

De Almeida C M, Gleriani J M (2005) Cellular automata and neural networks as modeling framework for the simulation of urban land use change. Anais XII Simpósio Brasileiro de Sensoriamento Remoto, Goiânia, Brasil, 16-21 abril, INPE: 3697-3705. 
Gong P (1996) Integrated analysis of spatial data from multiple sources: using evidential reasoning and artificial neural network techniques for geological mapping. Photogramm Eng Remote Sens 62:513-23

Gong JZ, Liu YS, Xia BC, Zhao GW (2009) Urban ecological security assessment and forecasting based on a cellular automata model: a case study of Guangzhou, china. Ecol Model 220:3612-20, doi:10.1016/j.ecolmodel.2009.10.018

He C, Okada N, Zhang Q, Shi P, Li J (2008) Modelling dynamic urban expansion processes incorporating a potential model with cellular automata. Landsc Urban Plan 86:79-91, doi:10.1016/j.landurbplan.2007.12.010

Kocabas V, Dragicevic S (2006) Assessing cellular automata model behavior using sensitivity analysis approach. Comput Environ Urban Syst 30(6):921-53, doi:10.1016/j.compenvurbsys.2006.01.001

Kocabas V, Dragicevic S (2007) Enhancing a GIS cellular automata model of land use change: Bayesian networks, influence diagrams and causality. Trans GIS 11(5):681-702, doi:10.1111/j.1467-9671.2007.01066.x

Li X, Liu X (2006) An extended cellular automaton using case-based reasoning for simulating urban development in a large complex region. Int J Geogr Inf Sc 20(10):1109-36, doi:10.1080/13658810600816870

Li X, Yeh AG (2001) Calibration of cellular automata by using neural networks for the simulation of complex urban systems. Environ Plan A 33:1445-62, doi:10.1068/a33210

Li X, Yeh AG (2002) Neural-network-based cellular automata for simulating multiple land use changes using GIS. Int J Geogr Inf Sci 16:323-43, doi:10.1080/13658810210137004

Li TH, Li WK, Qian ZH (2010) Variations in ecosystem service value in response to land use changes in Shenzhen. Ecol Econ 69(7):1427-35, doi:10.1016/j.ecolecon. 2008.05.018

Liu Y, Phinn SR (2003) Modeling urban development with cellular automata incorporating fuzzy-set approaches. Comput Environ Urban Syst 27:637-58, doi:10.1016/S0198-9715(02)00069-8

Liu X, Li X, Liu L, He J, Ai B (2008a) A bottom-up approach to discover transition rules of cellular automata using ant intelligence. Int J Geogr Inf Sci 22(11-12):1247-69, doi:10.1080/13658810701757510

Liu X, Li X, Shi X, Wu S, Liu T (2008b) Simulating complex urban development using kernel-based non-linear cellular automata. Ecol Model 211:169-81, doi:10.1016/j.ecolmodel.2007.08.024

Moller MFA (1993) A scaled conjugate gradient algorithm for fast supervised learning. Neural Netw 6:525-33

Pijanowski BC, Brown BG, Shellito BA, Manik GA (2002) Using neural networks and GIS to forecast land use changes: a land transformation model. Comput Environ Urban Syst 26:553-75, doi:10.1016/S0198-9715(01)00015-1

Santé I, García AM, Miranda D, Crecente R (2010) Cellular automata models for the simulation of real-world urban processes: a review and analysis. Landsc Urban Plan 96:108-22, doi:10.1016/j.landurbplan.2010.03.001

Shi PJ, Chen J, Pan Y (2000) Land use change mechanism in Shenzhen city. Acta Geograph Sin 55(2):151-60 (in Chinese)

Singh A K (2003) Modeling land use land cover changes using cellular automata in a geo-spatial environment. International Institute for Geo-Information Science and Earth Observation. Vol. Master of Science, Enscheda, the Netherlands.

Stevens D, Dragicevic S, Rothley K (2007) iCity: A GIS-CA modeling tool for urban planning and decision making. Environ Model Softw 22:761-73, doi:10.1016/j.envsoft.2006.02.004

Torrens P M (2000). How cellular models of urban systems work. (1. Theory). Centre for advanced spatial analysis working Paper Series 28 (ISSN: 1467-1298@ Copyright CASA, UCL.)

Torrens PM, O'Sullivan D (2001) Editorial: cellular automata and urban simulation: where do we go from here? Environm Plan B 28:163-8, doi:10.1068/b2802ed

Verburg PH, de Nijs TCM, von Eck JR, Visser H, Jong K (2004) A method to analyze neighborhood characteristics of land use patterns. Comput Environ Urban Syst 28:667-90, doi:10.1016/j.compenvurbsys.2003.07.001

Wang H, Li XB, Long HL, Qiao YW, Li Y (2011) Development and application of a simulation model for changes in land-use patterns under drought scenarios. Comput Geosci 37:831-43, doi:10.1016/j.cageo.2010.11.014

White R, Engelen G (2000) High-resolution integrated modeling of the spatial dynamics of urban and regional systems. Comput Environ Urban Syst 24:383-400, doi:10.1016/S0198-9715(00)00012-0

Wolfram S (1984) Cellular automata as models of complexity. Nature 311:419-24, doi:10.1038/311419a0

Wu F (1996) A linguistic cellular automata simulation approach for sustainable land development in a fast growing region. Comput Environ Urban Syst 20:367-87, doi:10.1016/S0198-9715(97)00003-3
Wu F (1998a) Simulating urban encroachment on rural land with fuzzy-logiccontrolled cellular automata in a geographical information system. J Environ Manag 53:293-308, doi:10.1006/jema.1998.0195

Wu F (1998b) SimLand: a prototype to simulate land conversion through the integrated GIS and CA with AHP-derived transition rules. Int J Geogr Inf Sci 12(1):63-82, doi:10.1080/136588198242012

Wu FL (2002) Calibration of stochastic cellular automata: the application to ruralurban land conversions. Int J Geogr Inf Sci 16(8):795-818, doi:10.1080/ 13658810210157769

Yang QS, Li X, Shi X (2008) Cellular automata for simulating land use changes based on support vector machines. Comput Geosci 34(6):592-602, doi:10.1016/j.cageo.2007.08.003

Yeh AG, Li X (2003) Simulation of development alternatives using neural networks, cellular automata, and GIS for urban planning. Photogramm Eng Remote Sens 69:1043-52

Yeh AG, Li X (2004) Integration of neural networks and cellular automata for urban planning. Geo Spatial Inf Sci Q 7:6-13

\section{Submit your manuscript to a SpringerOpen ${ }^{\circ}$ journal and benefit from:}

- Convenient online submission

- Rigorous peer review

- Immediate publication on acceptance

- Open access: articles freely available online

- High visibility within the field

- Retaining the copyright to your article

Submit your next manuscript at $>$ springeropen.com 